\title{
Point-of-use water treatment improves recovery rates among children with severe acute malnutrition in Pakistan: results from a site-randomized trial
}

\author{
Shannon Doocy ${ }^{1, *}$, Hannah Tappis ${ }^{1}$, Nicolas Villeminot ${ }^{2}$, Ann Suk ${ }^{1,3}$, Deepak Kumar ${ }^{3}$, \\ Shahid Fazal ${ }^{3}$, Angeline Grant ${ }^{2}$ and Silke Pietzsch ${ }^{2}$ \\ 'Johns Hopkins Bloomberg School of Public Health, Department of International Health, $615 \mathrm{~N}$. Wolfe Street, \\ Baltimore, MD 21205, US: ${ }^{2}$ Action Against Hunger USA, New York, NY, USA: ${ }^{3}$ Action Against Hunger Pakistan, \\ Islamabad, Pakistan
}

Submitted 28 August 2017: Final revision received 23 May 2018: Accepted 24 May 2018: First published online 22 August 2018

\begin{abstract}
Objective: To evaluate effectiveness of point-of-use water treatment in improving treatment of children affected by severe acute malnutrition (SAM).

Design: Programme sites were randomized to one of four intervention arms: (i) standard SAM treatment; (ii) SAM treatment plus flocculent/disinfectant water treatment; (iii) SAM treatment plus chlorine disinfectant; or (iv) SAM treatment plus ceramic water filter. Outcome measures were calculated based on participant status upon exit or after $120 \mathrm{~d}$ of enrolment, whichever came first. Child anthropometric data were collected during weekly monitoring at programme sites. Child caregivers were interviewed at enrolment and exit. Use of water treatment products was assessed in a home visit 4-6 weeks after enrolment.

Setting: Dadu District, Sindh Province, Pakistan.

Subjects: Children ( $n$ 901) aged 6-59 months with SAM and no medical complications.

Results: Recovery rates were $16 \cdot 7-22 \cdot 2 \%$ higher among children receiving water treatment compared with the control group. The adjusted odds of recovery were approximately twice as high for those receiving water treatment compared with controls. Mean length of stay until recovery was 73 (SD 24.6) d and mean rate of weight gain was 4.7 (sD 3.0) $\mathrm{g} / \mathrm{kg}$ per d. Differences in recovery rate, length of stay and rate of weight gain between intervention groups were not statistically significant.

Conclusions: Incorporating point-of-use water treatment into outpatient treatment programmes for children with SAM increased nutritional recovery rates. No significant differences in recovery rates were observed between the different intervention groups, indicating that different water treatment approaches were equally effective in improving recovery.
\end{abstract}

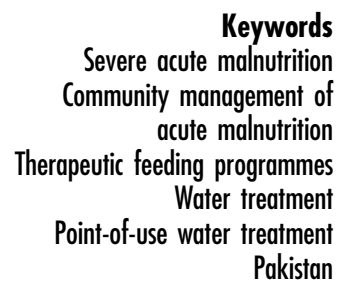

Malnutrition contributes to more than half the deaths among children under 5 years of age in developing countries and the association between malnutrition and mortality is well documented ${ }^{(1,2)}$. Severe acute malnutrition (SAM) persists as a significant problem, affecting at any one time an estimated 16.9 million children under 5 years old worldwide, with the largest number affected (9 million) in south-central $\mathrm{Asia}^{(3-5)}$. Over the past two decades, the development of ready-to-use therapeutic foods (RUTF) has resulted in a paradigm shift, with SAM cases now treated on an outpatient basis through community management of acute malnutrition (CMAM) programmes. CMAM is an effective decentralized outpatient approach to managing SAM that has several advantages compared with inpatient care, including higher coverage rates and lower opportunity costs for families ${ }^{(6)}$. The cost of rehabilitation in CMAM programmes remains high, with a large proportion of total costs going towards RUTF which are relatively expensive products that cost \$US $0.31-0.37$ per sachet and approximately \$US 33-60 per two-month treatment course (which requires $10-15 \mathrm{~kg}$ of RUTF) ${ }^{(6,7)}$. Despite the entry of new manufacturers into the market, prices of RUTF have not decreased substantially over time and gaps in product availability are 
anticipated to persist as a challenge in the future ${ }^{(8,9)}$. Increasing the efficiency of SAM treatment, by shortening treatment duration and thereby reducing the amount of RUTF required, could help humanitarian agencies and national governments to improve CMAM programming, which would enable the rehabilitation of more children with SAM.

Access to safe drinking-water remains a significant global challenge, where an estimated 1.8 billion people use faecally contaminated drinking-water sources that can lead to the transmission of diarrhoeal and other diseases ${ }^{(10)}$. Diarrhoeal diseases, which cause an estimated $10-15 \%$ of child deaths, have been described as both a cause and an effect of child undernutrition ${ }^{(5,11)}$. Undernutrition has been shown to lead to increased frequency and duration of diarrhoeal illness whereas diarrhoeal illness impairs weight and height gains, when illness is recurrent or when the child is severely malnourished ${ }^{(12)}$. The relationship between undernutrition and susceptibility to infections is complex and not fully understood. Traditional intervention strategies have focused largely on nutritional intake; however, it is recognized that new approaches, including those that address infection, are needed $^{(13)}$. In the context of CMAM programmes, where children with SAM are treated at home, access to safe drinking-water is a major concern, as consumption of contaminated water can lead to increased morbidity and mortality risk as well as reduce the efficacy of RUTF. Pointof-use water treatment has the potential to decrease exposure to diarrhoeal disease pathogens, reduce incidence of diarrhoeal disease and increase the speed of recovery of children with SAM, thereby reducing the length of enrolment in CMAM programmes, the amount of RUTF required for treatment and overall treatment costs.

The present study aimed to characterize the impacts of safe drinking-water during the treatment of children with SAM in areas with limited access to safe drinking-water. Study findings can serve as a basis for recommendations to improve SAM treatment protocols and have implications for both emergency and development settings where acute malnutrition is prevalent and access to safe drinkingwater is limited.

\section{Methods}

\section{Study location}

The present study evaluated the effectiveness of pointof-use water treatment within the context of CMAM programme sites supported by Action Against Hunger in Dadu District of Sindh Province in Pakistan. This research is especially pertinent to Pakistan, where over $50 \%$ of child deaths are linked to malnutrition ${ }^{(14)}$. The study took place in Sindh Province, where half (48\%) of children are stunted and the prevalence rates of global acute malnutrition and SAM are 15.4 and $3.6 \%$, respectively ${ }^{(15)}$.
Access to improved water sources is nearly universal in Sindh (93\%), with tube wells or boreholes, fitted with hand pumps, being the most common water source in rural areas and piped water in urban areas ${ }^{(15)}$. However, consumption of safe drinking-water remains a challenge as the majority of households (90\%) do not treat drinking-water and a predominance of water sources are contaminated; a recent study found that $77-92 \%$ of drinking-water from shallow pumps, dug wells and water supply schemes in Sindh Province were faecally contaminated $^{(15,16)}$. Inadequate access to sanitation is also a significant challenge as $86 \%$ of urban households and only $45 \%$ of rural households use improved non-shared toilet facilities ${ }^{(15)}$. As a result of the poor access to water and sanitation, diarrhoea is a common problem among young children in Sindh, with the prevalence rate of child diarrhoea estimated as between 23 and $35 \%$ (for a 2-week recall period) ${ }^{(17,18)}$.

\section{Sample size calculations}

Sample size calculations were determined based on the primary outcome of length of stay (LOS) in the CMAM programme and were informed by Action Against Hunger Dadu programme data and Sphere standards ${ }^{(19)}$. Calculations were based on the following assumptions: (i) mean LoS of 59 (sD 20) d; (ii) a reduction of $\geq 10 \mathrm{~d}$ in mean LoS, which is the point at which use of the flocculent/disinfectant method becomes cost-effective; (iii) a design effect of 2 to account for clustering by treatment unit/area; and (iv) a power $(1-\beta)$ of $80 \%$ and a significance level of $\alpha=0 \cdot 05$. Calculations were performed using the statistical software package Stata version 13 and the AI Therapy Statistics' sample size calculator (https://www.ai-therapy. $\mathrm{com} /$ psychology-statistics/sample-size-calculator) to ensure that the recommended sample size would be sufficient given that the number of children receiving care at each CMAM site cannot be controlled. Calculations yielded a minimum sample size of 170 children per group; the planned minimum sample size was increased to 200 children per group (800 children total) and the planned maximum sample size was 300 children per group (1200 children total) to account for loss to follow-up and possible differences in sample size between intervention groups.

\section{Study design}

Allocation of intervention groups was done by CMAM programme site because it increased the likelihood of fidelity to the planned intervention and because it was more feasible to implement than individual assignment. Blinding was not possible given the obviously different nature of the three point-of-use water treatment approaches and the need for a control group. Selection of CMAM sites accounted for other ongoing Action Against Hunger interventions, which resulted in the exclusion of some sites, either because of other ongoing intervention 
studies within the CMAM programme or because of widespread water and sanitation programming. A total of forty-one CMAM treatment sites were identified as potential sites for inclusion; six were subsequently excluded because of the logistical difficulties and cost of travel to access the sites. All sites were perceived by Action Against Hunger as having similarly acceptable levels of performance for CMAM performance indicators (recovery rate, treatment duration, weight gain, etc.). Eligible sites were assigned to four groups based on the following criteria: (i) projected caseload, such that reasonably similar numbers of SAM cases would present to facilities in each group during the study period; and (ii) urban/rural/rural remote CMAM site location, such that proportions of children in the caseload coming from each of these environments would be as similar as possible across comparison groups. The locations of each group of facilities were subsequently mapped to ensure balanced spatial coverage and were reviewed by field staff to ensure similarity and logistical feasibility. After agreement on the assignment of CMAM sites to four comparison groups, each group was randomly assigned to an intervention. A total of twenty CMAM sites in the Dadu, Johi, Khairpur Nathan Shah and Mehar talukas (or sub-districts) of Eastern Dadu District participated in the study (Fig. 1).

\section{Inclusion/exclusion criteria and enrolment}

Prospective participants were identified through enrolment at a participating CMAM site; the entry criterion for the CMAM treatment programme was a child mid-upper arm circumference (MUAC) of $<11.5 \mathrm{~cm}$. Children were ineligible for participation if they met one or more of the following criteria: (i) a diagnosis of kwashiorkor; or (ii) they required inpatient treatment for SAM because of other complicating condition(s); or (iii) their caregiver(s) were unwilling or unable to agree to their participation. Children graduating from inpatient treatment (i.e. no remaining medical complications) to the outpatient CMAM programme were eligible for participation. Exited children were classified as: (i) cured when MUAC $\geq 12.5 \mathrm{~cm}$ for two consecutive weeks; (ii) not recovered when MUAC $<12.5$ $\mathrm{cm}$ after $120 \mathrm{~d}$; (iii) defaulted when absent for two consecutive visits; or (iv) died during time registered in the CMAM programme. Children were eligible for inclusion in the study if they were: (i) between 6 and 59 months of age; (ii) diagnosed as an uncomplicated SAM case; (iii) enrolled in the CMAM programme at a participating site; and (iv) if the child's caregiver consented to participation.

Trained staff members conducted the recruitment. Caregivers of eligible children were given information about the study and participation was requested; caregivers were assured that their decision to participate would not impact their child's SAM treatment or access to other services. Informed consent was obtained by Action Against Hunger staff and included obtaining permission from the child's caregiver to enrol the child and consent for the household to participate in the study. Caregivers had the opportunity to ask questions regarding participation and, prior to the consent process, a description of the specific water treatment intervention at the site was given. Because of high illiteracy rates and the minimal risks associated with participation, oral permission and consent was obtained, as it is preferable not to have beneficiaries sign documents they cannot read. The study information and consent process were conducted in Sindhi or Urdu, depending on the participant's preference; similarly, data collection during the study was conducted in either language.

\section{Interventions}

SAM treatment was delivered through the existing CMAM programme sites and included a health screening, weekly provision of RUTF, weekly monitoring of child anthropometry and hygiene promotion ${ }^{(20)}$. Within the context of the CMAM programme, the following point-of-use water treatment interventions were assessed: (i) a flocculent/ disinfectant (Procter \& Gamble Purifier of Water (P\&G PoW)), which is commonly used in emergency settings and is particularly effective in the treatment of turbid water $^{(21,22)}$. The participants in the P\&G PoW group were provided with fourteen sachets of the water treatment product weekly during their CMAM visit (sufficient to treat 20 litres/d); (ii) a chlorine disinfectant (Aquatabs $67 \mathrm{mg}$; Medentech, Wexford, Republic of Ireland), which are a low-cost, locally available, mass-market water treatment option. The Aquatabs group was provided with seven Aquatabs weekly during their CMAM visit (sufficient to treat 20 litres/d); (iii) ceramic water filters (10" ceramic cartridges mounted on a plastic bucket; Aqua Fine, Lahore, Pakistan) that are available in Sindh Province and were delivered to the participant's home within a few days of enrolment; and (iv) water storage (control group), in which participants received a container to safely store water and continued to care for their water as usual. Caregivers in the P\&G PoW, Aquatabs and Ceramic Filter groups were instructed on how to use the product, including a demonstration and a take-home step-by-step guide, and were provided with necessary materials to use the product in addition to a safe water storage container.

\section{Data collection and analysis}

After consenting to participate, caregivers completed an enrolment interview, which included child and caregiver characteristics; household characteristics, living conditions and food security; and a Knowledge, Attitudes, Practices (KAP) survey on nutrition, water, sanitation and hygiene. Children's anthropometric data were collected during weekly monitoring at the CMAM sites and included MUAC, height/length and weight; quantity of RUTF distributed and occurrence of diarrhoea in the preceding week were 


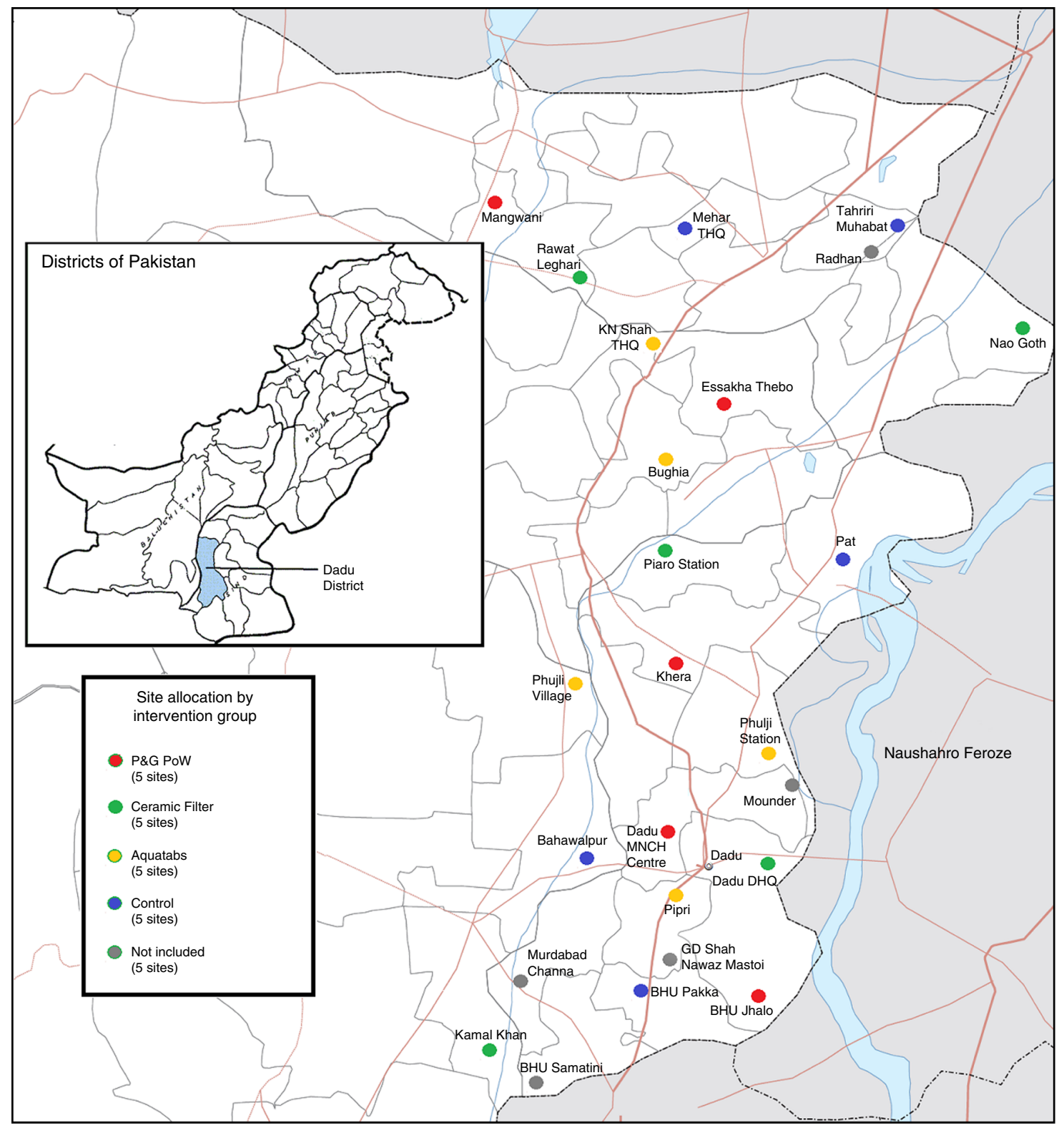

Fig. 1 (colour online) Maps showing Dadu District in Pakistan and allocation of sites within the district according to intervention group (THQ, Tehsil Headquarters Hospital; MNCH, maternal, newborn and child health; DHQ, District Headquarters Hospital; P\&G PoW, Proctor \& Gamble Purifier of Water)

also collected. A home visit was conducted approximately 4-6 weeks after enrolment to assess the use of water treatment products. Stored drinking-water was tested for free and total chlorine levels (P\&G PoW and Aquatabs groups (Free Chlorine Test Kit CN-66F; Hach, Loveland, CO, USA)) and for presence of faecal coliforms (all groups, unless high chlorine levels rendered testing unnecessary (One-Step Simple Water Test for Bacteriological Contamination; prepared and distributed by Pakistan Council of Research in Water Resources, Islamabad, Pakistan). Exit interviews were conducted using a similar questionnaire to the enrolment interview with additional questions on perceptions and utilization of the point-of-use treatment product. Data were collected using the Open Data Kit
(ODK) platform (https://opendatakit.org/) on encrypted devices; records were transferred to a database manually and then deleted from the mobile device.

Performance indicators and outcome measures were calculated based on participant status upon exit or after $120 \mathrm{~d}$ of enrolment, whichever came first. Primary outcome measures included: (i) mean LoS in the CMAM programme; (ii) average daily weight gain ( $\mathrm{g} / \mathrm{kg}$ per $\mathrm{d}$ ); and (iii) the recovery rate, which was the proportion of children exiting the programme cured. Analysis was conducted in Stata version 13 and included descriptive statistics, univariate and multivariate regression. Linear and logistic regression models were used to adjust for the age and sex of the child and for caregiver, household and site 
characteristics; a stepwise approach was used with $P>0.20$ as criterion for removal from the model.

\section{Results}

A total of 901 children were enrolled in the study, with 219 children enrolled at control sites, 231 at sites receiving Aquatabs, 220 at sites receiving ceramic filters and 231 at sites receiving P\&G PoW (Fig. 2). Children enrolled in each of the participant groups were similar at baseline in terms of most individual and household characteristics documented in enrolment interviews (Table 1). Children in the P\&G PoW and Aquatab groups had higher diarrhoea prevalence than children in the Control group, and children in the Aquatabs group had lower weight-forheight. Other differences between intervention and control groups included household access to an improved latrine, which remained low $(30 \cdot 2-42 \cdot 1 \%)$, and distance to a household's primary water source, although the time spent to fetch water did not highlight difficulties to access water ( 8.6 to $16.1 \mathrm{~min}$ to the water source). While differences in mean household hunger score were statistically significant, scores indicated little to no hunger in any of the groups, suggesting that food insecurity was not a major concern at the time the study was conducted. Across all groups, $4 \%$ of participants did not complete the study (Fig. 2). Participants who were referred to a nutrition stabilization centre or another facility for medical complications and participants who migrated out of the programme area were considered lost to follow-up. This included $2 \%(n 5)$ of children in the Aquatabs group, $6 \%$ ( $n$ 14) in the Ceramic Filter group, $5 \%(n 11)$ in the P\&G PoW group and $3 \%(n 6)$ in the Control group.
Ultimately, 865 children completed the study: 213 in the Control group, 222 in the Aquatabs group, 205 in the Ceramic Filter group and 218 in the P\&G PoW group. Recovery rates were significantly higher in all three intervention groups than in the Control group (Table 2) but, except for the Aquatabs group, did not meet Sphere standards of at least $75 \%$ of children in the programme recovering. Differences in recovery rates between intervention and control groups ranged from $16 \cdot 6$ percentage points for the P\&G PoW group $(P<0.001)$, to 17.6 percentage points for the Ceramic Filter group $(P<0 \cdot 001)$ and $22 \cdot 1$ percentage points for the Aquatabs group $(P<0 \cdot 001)$; differences in recovery rates among intervention groups were not statistically significant. All groups met Sphere standards for mortality rates $(<10 \%)$ and default rates ( $<15 \%)$; however, non-response rates were high (ranging from 19.4 to $33.0 \%$ ) across all groups. Children who remained in the programme for $120 \mathrm{~d}$ but did not have an increase in MUAC to $>12.5 \mathrm{~cm}$ were considered nonresponsive or non-recovered. LoS until recovery ranged from 21 to $120 \mathrm{~d}$, with a mean stay of 73 (sD 24.6) d. Mean rate of weight gain was 4.7 (SD 3.0) $\mathrm{g} / \mathrm{kg}$ per d. Differences in LoS and rate of weight gain between groups were not statistically significant (Table 2).

Adjusting for differences in child and household characteristics (including child age, sex, MUAC and diarrhoea prevalence, and household food insecurity) in a logistic regression model, all treatments were found to significantly increase the odds of recovery within $120 \mathrm{~d}$ (Table 3). After adjusting for these factors, odds ratios ranged from 1.9 (95\% CI 1.2, 2.8; $P<0 \cdot 001)$ for P\&G PoW and ceramic filters to 2.5 (95\% CI $1.7,3.9 ; P<0.001)$ for Aquatabs; differences in adjusted odds of recovery between treatment groups were not statistically significant. Independent of treatment effects, children from

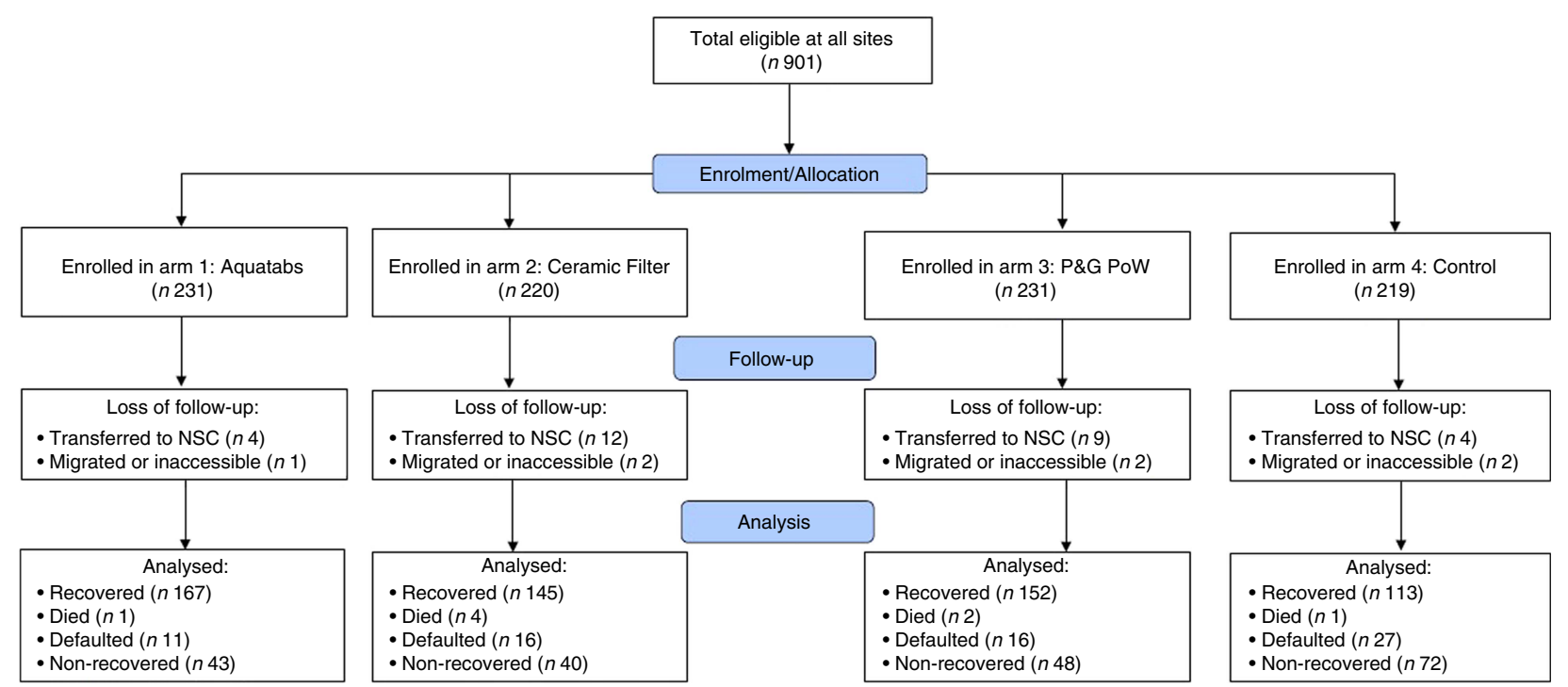

Fig. 2 (colour online) Flowchart of study participation (P\&G PoW, Proctor \& Gamble Purifier of Water; NSC, nutrition stabilization centre) 
Table 1 Characteristics of the study population at baseline (February-May 2016): children aged 6-59 months with severe acute malnutrition (with no medical complications) and their families, Dadu District, Sindh Province, Pakistan

\begin{tabular}{|c|c|c|c|c|c|c|c|c|c|c|}
\hline & \multirow{2}{*}{$\begin{array}{c}\begin{array}{c}\text { Control } \\
(n 219)\end{array} \\
\begin{array}{c}\text { Point } \\
\text { estimate } \\
(\%)\end{array}\end{array}$} & \multicolumn{3}{|c|}{$\begin{array}{l}\text { Aquatabs } \\
(n 231)\end{array}$} & \multicolumn{3}{|c|}{$\begin{array}{l}\text { P\&G PoW } \\
(n 231)\end{array}$} & \multicolumn{3}{|c|}{$\begin{array}{l}\text { Ceramic Filter } \\
\quad(n 220)\end{array}$} \\
\hline & & $\begin{array}{c}\text { Point } \\
\text { estimate } \\
(\%)\end{array}$ & $\begin{array}{l}\text { Difference } \\
\text { from } \\
\text { Control }\end{array}$ & $P$ value & $\begin{array}{c}\text { Point } \\
\text { estimate } \\
(\%)\end{array}$ & $\begin{array}{c}\text { Difference } \\
\text { from } \\
\text { Control }\end{array}$ & $P$ value & $\begin{array}{c}\text { Point } \\
\text { estimate } \\
(\%)\end{array}$ & $\begin{array}{c}\text { Difference } \\
\text { from } \\
\text { Control }\end{array}$ & $P$ value \\
\hline \multicolumn{11}{|l|}{ Child characteristics } \\
\hline Aged 5-11 months & $60 \cdot 3$ & $63 \cdot 2$ & 2.9 & 0.999 & $60 \cdot 0$ & -0.3 & 0.790 & $62 \cdot 7$ & $2 \cdot 5$ & 0.992 \\
\hline Aged $12-23$ months & $26 \cdot 0$ & $25 \cdot 1$ & -0.9 & & $28 \cdot 1$ & $2 \cdot 1$ & & $26 \cdot 4$ & 0.3 & \\
\hline Aged $24-60$ months & $13 \cdot 7$ & $11 \cdot 7$ & $-2 \cdot 0$ & & $11 \cdot 3$ & $-2 \cdot 4$ & & $10 \cdot 9$ & $-2 \cdot 8$ & \\
\hline Female & $57 \cdot 1$ & $58 \cdot 0$ & 0.9 & 0.168 & $62 \cdot 8$ & $5 \cdot 7$ & 0.994 & $66 \cdot 4$ & $9 \cdot 3$ & 0.589 \\
\hline Male & $42 \cdot 9$ & $42 \cdot 0$ & -0.9 & & 37.2 & $-5 \cdot 7$ & & 33.6 & -9.3 & \\
\hline Mean MUAC $(\mathrm{cm})$ & $10 \cdot 8$ & $10 \cdot 8$ & 0.0 & 1.000 & $10 \cdot \overline{8}$ & 0.0 & 1.000 & $10 \cdot 7$ & -0.1 & 0.808 \\
\hline Mean WHZ & $-3 \cdot 2$ & -3.5 & -0.3 & 0.030 & $-3 \cdot 4$ & -0.2 & 0.257 & -3.4 & -0.2 & 0.251 \\
\hline Diarrhoea in past week & $29 \cdot 2$ & $36 \cdot 8$ & $7 \cdot 6$ & 0.208 & $41 \cdot 6$ & $12 \cdot 4$ & 0.028 & $25 \cdot 5$ & $-3 \cdot 8$ & 0.559 \\
\hline \multicolumn{11}{|l|}{ Household characteristics } \\
\hline Rural & $77 \cdot 6$ & $72 \cdot 7$ & -4.9 & 0.474 & $77 \cdot 1$ & -0.5 & 0.998 & $77 \cdot 3$ & -0.3 & 1.000 \\
\hline Urban & 22.4 & $27 \cdot 3$ & 4.9 & & $22 \cdot 9$ & 0.5 & & $22 \cdot 7$ & 0.3 & \\
\hline Household size & $9 \cdot 3$ & 8.9 & -0.4 & 0.502 & 9.4 & 0.1 & 0.998 & 9.1 & -0.2 & 0.845 \\
\hline $\begin{array}{l}\text { No. of children } \\
<5 \text { years }\end{array}$ & 2.9 & $2 \cdot 6$ & -0.3 & 0.112 & $2 \cdot 8$ & 0.1 & 0.952 & $2 \cdot 8$ & 0.0 & 0.962 \\
\hline $\begin{array}{l}\text { Household hunger } \\
\text { score }^{*}\end{array}$ & $1 \cdot 0$ & 0.4 & -0.6 & $<0.001$ & 0.4 & -0.6 & $<0.001$ & 0.5 & -0.6 & $<0.001$ \\
\hline $\begin{array}{l}\text { Access to improved } \\
\text { latrine }\end{array}$ & $30 \cdot 2$ & $42 \cdot 1$ & 11.9 & 0.030 & $35 \cdot 7$ & 5.5 & 0.513 & $41 \cdot 3$ & $11 \cdot 1$ & 0.050 \\
\hline $\begin{array}{l}\text { Protected water } \\
\text { source }\end{array}$ & $87 \cdot 2$ & $82 \cdot 3$ & $-5 \cdot 0$ & 0.237 & $89 \cdot 6$ & $2 \cdot 4$ & 0.766 & $94 \cdot 1$ & $6 \cdot 9$ & 0.064 \\
\hline \multicolumn{11}{|l|}{ Water source location } \\
\hline Home/compound & $62 \cdot 1$ & $52 \cdot 4$ & -9.7 & 0.772 & 83.9 & 21.8 & $<0.001$ & $65 \cdot 0$ & $2 \cdot 9$ & 0.253 \\
\hline In village & $22 \cdot 8$ & 35.5 & $12 \cdot 7$ & & $13 \cdot 0$ & -9.8 & & $26 \cdot 8$ & 4.0 & \\
\hline Outside village & $13 \cdot 2$ & $12 \cdot 1$ & $-1 \cdot 1$ & & 3.0 & $-10 \cdot 2$ & & 6.8 & $-6 \cdot 4$ & \\
\hline Other & 1.8 & 0.0 & -1.8 & & 0.0 & -1.8 & & 1.4 & -0.5 & \\
\hline $\begin{array}{l}\text { Minutes to water } \\
\text { source }\end{array}$ & $11 \cdot 4$ & $16 \cdot 1$ & $4 \cdot 7$ & $<0.001$ & 8.6 & -2.9 & 0.052 & $9 \cdot 7$ & $-1 \cdot 7$ & 0.353 \\
\hline \multicolumn{11}{|l|}{ Water storage container } \\
\hline Open container & 93.6 & $92 \cdot 2$ & -1.4 & 0.883 & 93.9 & -0.3 & 0.998 & 93.6 & 0.0 & 1.000 \\
\hline Cleanable container & $70 \cdot 8$ & 59.7 & $-11 \cdot 0$ & 0.029 & $77 \cdot 5$ & $-6 \cdot 7$ & 0.278 & $69 \cdot 6$ & $-1 \cdot 2$ & 0.985 \\
\hline $\begin{array}{l}\text { Water treatment use } \\
\text { (any) }\end{array}$ & $10 \cdot 1$ & 9.1 & -1.0 & 0.963 & 4.4 & $-5 \cdot 7$ & 0.056 & $6 \cdot 4$ & $-3 \cdot 7$ & 0.321 \\
\hline $\begin{array}{l}\text { Boiling } \\
\text { Cloth filter }\end{array}$ & $\begin{array}{l}27 \cdot 3 \\
72 \cdot 7\end{array}$ & $\begin{array}{r}9.5 \\
90.5\end{array}$ & $\begin{array}{r}-17.8 \\
17.8\end{array}$ & 0.251 & $\begin{array}{l}10 \cdot 0 \\
90 \cdot 0\end{array}$ & $\begin{array}{r}-17 \cdot 3 \\
17 \cdot 3\end{array}$ & 0.445 & $\begin{array}{r}7 \cdot 1 \\
92 \cdot 9\end{array}$ & $\begin{array}{r}-20 \cdot 1 \\
20 \cdot 1\end{array}$ & 0.242 \\
\hline
\end{tabular}

P\&G PoW, Proctor \& Gamble Purifier of Water; MUAC, mid-upper arm circumference; WHZ, weight-for-height Z-score.

Significant $P$ values are indicated in bold.

*Scale of $0-6$, where a higher score indicates more hunger.

†Includes piped water, public taps, tube wells/boreholes, protected dug wells and protected springs.

households with access to a protected water source were $2 \cdot 3$ times more likely to recover within $120 \mathrm{~d}$ than children from households without a protected water source (95\% CI $1.5,3.5 ; P<0 \cdot 001)$. Accounting for interactions between treatments and access to a protected water source did not significantly modify the odds of recovery within $120 \mathrm{~d}$ (data not shown). Each $1 \mathrm{~cm}$ increase in MUAC at enrolment also significantly increased the odds of recovery within $120 \mathrm{~d}(\mathrm{OR}=1 \cdot 5 ; 95 \% \mathrm{CI} 1 \cdot 2,1 \cdot 8, P=0 \cdot 001)$, while diarrhoea prevalence reduced odds of recovery by $60 \%$ (OR=0.4; 95\% CI 0.2, 0.9; $P=0.029)$ and food insecurity, measured by household hunger score, decreased the odds of recovery by $10 \%(\mathrm{OR}=0.9 ; 95 \% \mathrm{CI} 0 \cdot 8,1 \cdot 0 ; P=0.008)$.

Among children who recovered within $120 \mathrm{~d}$, MUAC and diarrhoea prevalence were found to have a significant association with treatment duration required to meet exit criteria (Table 3). After adjusting for treatment group and other child and household characteristics, each $1 \mathrm{~cm}$ increase in MUAC at enrolment was found to significantly decrease LoS in the programme by $7 \cdot 1 \mathrm{~d}$ (95\% CI $-10 \cdot 3$, $-3.8 \mathrm{~d} ; P<0.001)$. In contrast, longitudinal prevalence of diarrhoea during the study period was found to significantly increase LoS by $11.1 \mathrm{~d}$ (95\% CI $0.4,21.8 \mathrm{~d}$; $P=0 \cdot 042$ ) per prevalent week.

Water quality testing conducted approximately 4-6 weeks after enrolment revealed relatively high levels of faecal contamination in household water supplies, with positive bacteriology tests in at least one-third of households in all treatment groups. Water contamination was most prevalent in Control group households (55\%). Aquatabs and P\&G PoW groups had significantly lower prevalence of contamination, with 37.3 and $33.9 \%$ of households showing positive bacteriology, respectively. There was not a statistically significant difference in prevalence of water contamination between the Ceramic Filter and Control groups. Children in the Aquatabs group had significantly lower longitudinal prevalence of diarrhoea than children in the Control group during the study period (20 v. 26\%; $P=0.006$ ), which may have contributed to recovery rates in this group. Diarrhoea prevalence among Ceramic Filter and P\&G PoW groups did not vary significantly from the Control group. 
Table 2 Intervention outcomes among the study population: children aged 6-59 months with severe acute malnutrition (with no medical complications), Dadu District, Sindh Province, Pakistan

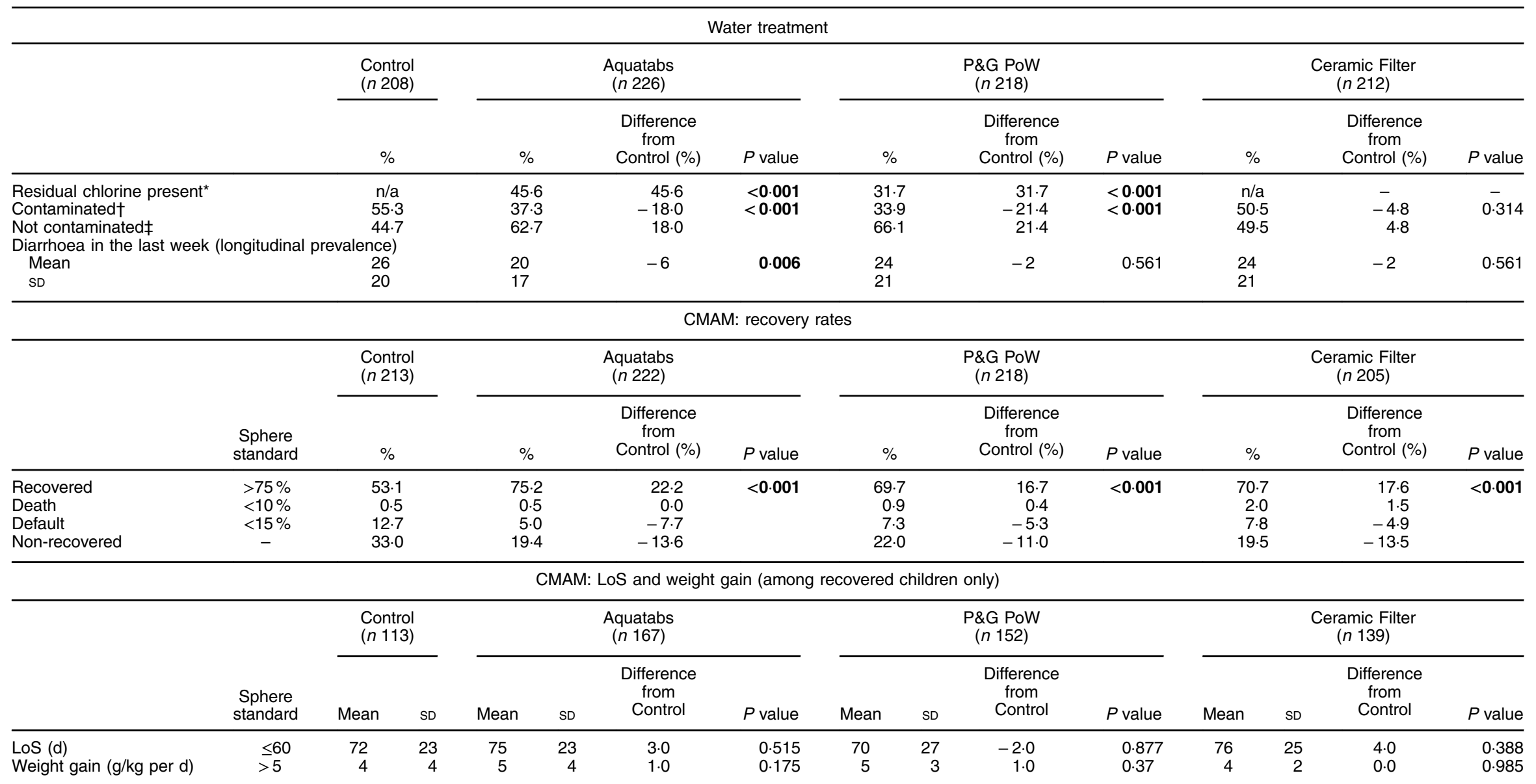

P\&G PoW, Proctor \& Gamble Purifier of Water; CMAM, Community Management of Acute Malnutrition; LoS, length of stay; n/a, not applicable,

Significant $P$ values are indicated in bold.

*Not measured for the Control and Ceramic Filter arms; presumed to be zero since no households reported use of chlorine-based water treatment at enrolment.

†Positive bacteriology.

Negative bacteriology or residual chlorine presence. 
Table 3 Odds of recovery and length of stay among children aged 6-59 months with severe acute malnutrition (with no medical complications), Dadu District, Sindh Province, Pakistan

\begin{tabular}{|c|c|c|c|c|c|c|c|c|}
\hline & \multicolumn{8}{|c|}{ Logistic regression model: recovery } \\
\hline & \multicolumn{4}{|c|}{ Unadjusted } & \multicolumn{4}{|c|}{ Adjusted } \\
\hline & OR & $95 \% \mathrm{Cl}$ & SE & $P$ value & OR & $95 \% \mathrm{Cl}$ & SE & $P$ value \\
\hline Control & \multicolumn{4}{|c|}{ (Reference) } & \multicolumn{4}{|c|}{ (Reference) } \\
\hline Aquatabs & $2 \cdot 7$ & $1 \cdot 8,4 \cdot 0$ & 0.6 & $<0.001$ & 2.5 & $1.7,3.9$ & 0.6 & $<0.001$ \\
\hline Ceramic Filter & $2 \cdot 1$ & $1 \cdot 4,3 \cdot 2$ & 0.4 & $<0.001$ & 1.9 & $1 \cdot 2,2.9$ & 0.4 & 0.001 \\
\hline P\&G PoW & $2 \cdot 0$ & $1.4,3.0$ & 0.4 & $<0.001$ & 1.9 & $1 \cdot 2,2 \cdot 8$ & 0.4 & $<0.001$ \\
\hline Aged $5-11$ months & \multicolumn{4}{|c|}{ (Reference) } & \multicolumn{4}{|c|}{ (Reference) } \\
\hline Aged 12-23 months & $1 \cdot 1$ & $0.8,1.6$ & 0.2 & 0.456 & 1.0 & $0.8,1.4$ & 0.2 & 0.914 \\
\hline Aged $24-60$ months & $1 \cdot 1$ & $0.7,1.8$ & 0.3 & 0.634 & 1.0 & $0.6,1.7$ & 0.2 & 0.881 \\
\hline Female & \multicolumn{4}{|c|}{ (Reference) } & \multicolumn{4}{|c|}{ (Reference) } \\
\hline Male & $1 \cdot 0$ & $0.8,1.4$ & 0.2 & 0.838 & $1 \cdot 1$ & $0.8,1.5$ & 0.2 & 0.680 \\
\hline MUAC at enrolment $(\mathrm{cm})$ & 1.4 & $1 \cdot 1,1 \cdot 7$ & $0 . \overline{2}$ & 0.001 & 1.5 & $1 \cdot 2,1 \cdot 8$ & 0.2 & 0.001 \\
\hline Protected water source & $2 \cdot 0$ & $1.3,3.0$ & 0.4 & 0.001 & $2 \cdot 3$ & $1.5,3.5$ & 0.5 & $<0.001$ \\
\hline $\begin{array}{l}\text { Diarrhoea in the last week } \\
\text { (longitudinal prevalence) }\end{array}$ & 0.3 & $0.2,0.7$ & 0.1 & 0.003 & 0.4 & $0.2,0.9$ & $0 \cdot 2$ & 0.029 \\
\hline \multirow[t]{4}{*}{ Household hunger score } & 0.8 & $0.7,0.9$ & 0.0 & $<0.001$ & 0.9 & $0 \cdot 8,1 \cdot 0$ & 0.1 & 0.008 \\
\hline & \multicolumn{8}{|c|}{ Linear regression model: length of stay among recovered children } \\
\hline & \multicolumn{4}{|c|}{ Unadjusted } & \multicolumn{4}{|c|}{ Adjusted } \\
\hline & Coefficient & $95 \% \mathrm{Cl}$ & SE & $P$ value & Coefficient & $95 \% \mathrm{Cl}$ & $\mathrm{SE}$ & $P$ value \\
\hline Control & \multicolumn{4}{|c|}{ (Reference) } & \multicolumn{4}{|c|}{ (Reference) } \\
\hline Aquatabs & $3 \cdot 1$ & $-2 \cdot 7,9 \cdot 0$ & 3.0 & 0.297 & $3 \cdot 1$ & $-2 \cdot 6,8.9$ & 2.9 & 0.287 \\
\hline Ceramic Filter & $5 \cdot 2$ & $-0.9,11.2$ & $3 \cdot 1$ & 0.094 & 4.9 & $-1.0,10 \cdot 9$ & 3.0 & 0.104 \\
\hline P\&G PoW & $-2 \cdot 3$ & $-8.3,3.7$ & 3.0 & 0.449 & $-1 \cdot 2$ & $-7 \cdot 1,4 \cdot 7$ & 3.0 & 0.687 \\
\hline Rural & \multicolumn{4}{|c|}{ (Reference) } & \multicolumn{4}{|c|}{ (Reference) } \\
\hline Urban & $-4 \cdot 7$ & $-9.4,0.0$ & 2.4 & 0.051 & -4.5 & $-9.2,0.2$ & 2.4 & 0.063 \\
\hline Aged 5-11 months & \multicolumn{4}{|c|}{ (Reference) } & \multicolumn{4}{|c|}{ (Reference) } \\
\hline Aged $12-23$ months & -4.9 & $-10.6,0.9$ & 2.9 & 0.099 & 0.4 & $-4 \cdot 2,5 \cdot 0$ & 2.3 & 0.867 \\
\hline Aged $24-60$ months & $-5 \cdot 8$ & $-13 \cdot 6,2 \cdot 1$ & 4.0 & 0.149 & $-2 \cdot 0$ & $-8.4,4.4$ & 3.3 & 0.536 \\
\hline Female & \multicolumn{4}{|c|}{ (Reference) } & \multicolumn{4}{|c|}{ (Reference) } \\
\hline Male & -0.7 & $-5 \cdot 7,4 \cdot 4$ & 2.6 & 0.793 & -1.0 & $-5 \cdot 0,-3.0$ & $2 \cdot 1$ & 0.631 \\
\hline MUAC at enrolment $(\mathrm{cm})$ & $-4 \cdot 3$ & $-7.9,-0.8$ & 1.8 & 0.017 & $-7 \cdot 1$ & $-10 \cdot 3,-3 \cdot 8$ & 1.6 & $<0.001$ \\
\hline $\begin{array}{l}\text { Diarrhoea in the last week } \\
\text { (longitudinal prevalence) }\end{array}$ & $11 \cdot 3$ & $0.5,22 \cdot 1$ & $5 \cdot 5$ & 0.040 & $11 \cdot 1$ & $0.4,21.8$ & $5 \cdot 4$ & 0.042 \\
\hline
\end{tabular}

P\&G PoW, Proctor \& Gamble Purifier of Water; MUAC, mid-upper arm circumference.

Significant $P$ values are indicated in bold.

Note: Differences between treatment effects in adjusted model are not statistically significant.

\section{Discussion}

In the present site-randomized trial, provision of water treatment products significantly increased nutritional recovery of acutely malnourished children in an outpatient treatment programme. Recovery rates were 16.7 to $22 \cdot 2 \%$ higher among children receiving water treatment compared with the control group and the adjusted odds of recovery were approximately twice as high for those receiving water treatment compared with controls. These findings suggest that various types of water treatment products can be effective in improving treatment outcomes in CMAM programmes. These findings are consistent with evidence from Chad, where children in CMAM programmes who received water treatment also had significantly greater recovery rates compared with those receiving the standard care ${ }^{(23)}$.

However, the mechanism by which water treatment impacted treatment outcomes remains unclear. Lower diarrhoea prevalence was associated with increased odds of recovery, but the hypothesis that safe drinking-water would reduce diarrhoea prevalence, thereby resulting in faster recovery, did not hold. Longitudinal prevalence of diarrhoea was only 2-6\% lower among children in water treatment groups compared with controls and differences in LoS in treatment between groups were not statistically significant. This suggests that diarrhoeal pathogens may be contracted through pathways other than drinking-water, including hands and food, and that other determinants such as poor hygiene practices and environmental contamination may also need to be addressed to achieve larger reductions in diarrhoea prevalence.

Another potential explanation is lower than expected uptake of water treatment. In the Aquatabs and P\&G PoW groups, residual chlorine was found in stored drinkingwater in 45.6 and $31.7 \%$ of households, respectively, at an unannounced visit, suggesting that water treatment use may not have been consistent. Households receiving 
chlorine-based treatment had bacterial contamination rates significantly below (18.0-21.4\%) that of the control group whereas no significant difference in bacterial contamination was observed between the ceramic filter and control groups, suggesting that water disinfection was fully successful in only a minority of intervention households. This was confirmed in qualitative interviews, where participants reported lack of perceived value of water treatment and insufficient time as reasons for delaying or inconsistently using water treatment products.

The intervention did not include continued education or promotion of water treatment products past the initial enrolment visit where households were assigned to a treatment group and educated on the use of a specific water treatment product. Efforts to promote increased uptake, either at weekly CMAM visits or at the home, could have helped to increase utilization of water treatment and change beneficiary perceptions of its value. Household water treatment has been shown to reduce diarrhoea prevalence in other settings ${ }^{(24)}$, thus better adherence to water treatment and safe water storage could strengthen the benefits of water treatment observed in the present study by reducing prevalence of diarrhoea. In the current study, water quality was assessed on a single household visit using a qualitative presence/absence test. Quantitative measures could have provided valuable information on the exposure to risks to faecal coliforms and other pathogens, where there is an established relationship between bacterial concentration and risk of diarrhoeal disease ${ }^{(25)}$. Future studies to better understand the role of safe drinking-water and diarrhoea in SAM recovery should test water quality more frequently using quantitative measures as well as assess the severity of diarrhoeal episodes.

While the hypothesized pathway of improved water quality translating to reductions in both diarrhoea prevalence and length of treatment did not hold, there are several alternative explanations for the higher recovery rates observed among children in the intervention groups. First, it is possible that receipt of water treatment products served as a participation incentive. This hypothesis is supported by similarities in LoS of recovered children across all study groups and the higher proportion of nonrecovered children in the control group (33.0\%) compared with the intervention groups (19.4-22.0\%). If this hypothesis is correct, receipt of water treatment products may have encouraged parents to visit treatment centres more, thereby increasing the proportion of children who regularly received RUTF which translated to a lower proportion of non-responders and higher recovery rates. A second and related explanation is bias, due to the nonblinded study design, where parents of children in the water treatment groups were more consistent in adherence to CMAM protocols in the home, notably RUTF provision, or had improved hygiene behaviours. In this scenario, the presence and use of water treatment products in the household may have served as a reminder or incentive for improved feeding, hygiene and care practices. Different hygiene and/or feeding behaviours of caregivers in the intervention groups compared with the control group may have biased the study and contributed to the observed differences in recovery rates between children receiving water treatment and the control group.

The mean LoS, which ranged from 70 to $76 \mathrm{~d}$ and was statistically similar across groups, exceeded the Sphere standard of $60 \mathrm{~d}$. It was consistent with findings from CMAM programmes in Northern Pakistan where mean LoS was $70 \mathrm{~d}^{(26)}$. The observed LoS was greater than those reported in other Action Against Hunger-supported programmes in Sindh, which may be the result of differences in exit criteria between the national Pakistani protocol $($ MUAC $>11.5 \mathrm{~cm}$ ) and the study protocol $($ MUAC $>12.5 \mathrm{~cm}$ ). The study protocol is based on WHO recommendations ${ }^{(27)}$ that children with SAM be discharged at MUAC $>12.5 \mathrm{~cm}$. Other studies have demonstrated that changes in admission and discharge criteria affect CMAM performance indicators such as $\operatorname{LoS}^{(28)}$. Use of the $12.5 \mathrm{~cm}$ exit criterion as compared with the national protocol exit criterion (MUAC $>11.5 \mathrm{~cm}$ ) also contributed to higher non-recovered rates in the study than those observed under normal CMAM programming in Sindh, as children in the national protocol have $120 \mathrm{~d}$ to reach $11.5 \mathrm{~cm}$ whereas children in the study had $120 \mathrm{~d}$ to reach $12 \cdot 5 \mathrm{~cm}$.

\section{Limitations}

Sample size calculations used LoS data that differed greatly from LoS observed in the study; this may have resulted in an inappropriate estimation of sample size and inability to detect results as anticipated for some indicators. The absence of a Supplementary Feeding Programme in the area led to children being kept in treatment until they reached $12.5 \mathrm{~cm}$, which resulted in children remaining in the CMAM programme for longer than anticipated in the study design; this was corrected for in the LoS analysis but may have contributed to the lower recovery rates observed in the study compared with those reported from CMAM programme performance data. Enrolment occurred over a period of several months and differences in rate of enrolment across groups could have contributed to a seasonal bias: the Ceramic Filter and Control groups enrolled fewer children over the first two months (February-March) than Aquatabs and P\&G PoW groups, then caught up with higher enrolments in May, leading to proportionally more children still in treatment during the lean season (from July to October) in the Ceramic Filter and Control groups. The added scrutiny of the research may also have contributed to enforcing more rigorous MUAC measurements and discharge criteria than in regular programmes. Finally, the study would have benefited from an increased number of household visits with water 
testing and quantitative testing which provides estimates of bacterial load.

\section{Conclusions}

Incorporating point-of-use water treatment into outpatient treatment programmes for children with SAM increased nutritional recovery rates. No significant differences in recovery rates were observed between the different intervention groups, indicating that different water treatment approaches were equally effective in improving recovery. These findings are aligned with results from a similar study in Chad which also observed that water treatment resulted in increased recovery rates among children with SAM in outpatient treatment programmes ${ }^{(23)}$. These studies represent an emerging evidence base that suggests that in areas without widespread access to safe drinking-water, introduction of point-of-use water treatment technologies as an element of CMAM treatment protocols may be beneficial. Addition of water treatment to national protocols for treatment of children with SAM may contribute to improved recovery rates in outpatient treatment programmes, in addition to potentially having benefits in terms of cost-effectiveness ( $\mathrm{E}$ Rogers, $\mathrm{H}$ Tappis, S Doocy et al., unpublished results). While the introduction of water treatment resulted in increased recovery rates, more research is needed to understand the pathway to achieving this outcome, particularly given that substantial reductions in diarrhoea prevalence were not observed among children in the treatment groups as was hypothesized. Prevalence of diarrhoea was, however, found to strongly reduce odds of recovery, confirming the necessity to address the water, sanitation and hygiene risks that are estimated to account for $58 \%$ of diarrhoeal diseases in low- and middleincome countries ${ }^{(29)}$. Understanding the casual pathways and linkages between provision of water treatment technologies and improved CMAM programme outcomes such as recovery is critical for informing recommendations for changes to national protocols and programme implementation.

\section{Acknowledgements}

Acknowledgements: The authors are grateful to the Action Against Hunger Pakistan programme team, particularly Sardar Ali Shah and Mohsin Khan, for their support in implementing this study and to Maureen Gallagher of Action Against Hunger USA for technical consultations on study design. Financial support: This research project was funded by Elrha's Research for Health in Humanitarian Crises (R2HC) Programme, which aims to improve health outcomes by strengthening the evidence base for public health interventions in humanitarian crises, and by Procter
\& Gamble, whose Purifier of Water product was one of the three point-of-use water treatment options tested. The R2HC programme is funded equally by the Wellcome Trust and the UK Government (DFID). Elhra's R2HC Programme and Procter \& Gamble had no role in the design, analysis or writing of this article. Conflict of interest: None declared. Authorship: S.D. and S.P. designed the study. N.V., A.S., D.K., S.F., A.G. and S.P. contributed to study implementation. H.T., D.K. and S.F. conducted the analysis. H.T., S.D., N.V., D.K., S.F. and S.P. contributed to interpretation of results. S.D. and H.T. wrote the first draft, and all authors contributed to the review and revision of the manuscript. Ethics of human subject participation: This study was conducted according to the guidelines laid down in the Declaration of Helsinki and all procedures involving human subjects were approved by the National Bioethics Committee in Pakistan and the Institutional Review Board at Johns Hopkins Bloomberg School of Public Health. Verbal informed consent was obtained from all subjects. Verbal consent was witnessed and formally recorded. The study was registered with ClinicalTrials.gov (NCT02751476).

\section{References}

1. Pelletier DL, Frongillo EA Jr, Schroeder DG et al. (1995) The effects of malnutrition on child mortality in developing countries. Bull World Health Organ 73, 443-448.

2. Black RE, Allen AH, Bhutta ZA et al. (2008) Maternal and child undernutrition: global and regional exposures and health consequences. Lancet 371, 243-260.

3. UNICEF, World Health Organization \& World Bank Group (2017) Levels and Trends in Child Malnutrition. UNICEF/ WHO/World Bank Group Joint Child Malnutrition Estimates: Key Findings of the 2017 Edition. https://data.unicef. org/wp-content/uploads/2017/06/JME-2017_brochure_June25.pdf (accessed June 2018).

4. Black RE, Victora CG, Walker SP et al. (2013) Maternal and child undernutrition and overweight in low and middle income countries. Lancet 382, 427-451.

5. Black RE, Cousens S, Johnson HL et al. (2010) Global, regional and national causes of child mortality in 2008: a systematic analysis. Lancet 375, 1969-1987.

6. World Health Organization, World Food Programme, UN Standing Committee on Nutrition et al. (2007) Community Based Management of Severe Acute Malnutrition. A Joint Statement by the World Health Organization, the World Food Programme, the United Nations System Standing Committee on Nutrition and the United Nations Children's Fund. http://www.who.int/nutrition/publications/ severemalnutrition/978-92-806-4147-9_eng.pdf (accessed June 2018).

7. UNICEF (2018) Ready to Use Therapeutic Food Price Data, 2016. https://www.unicef.org/supply/index_59716.html (accessed June 2018).

8. Shoham J, Dolan C \& Gostelow L (2013) Managing acute malnutrition at scale: a review of donor and government financing arrangements. https://odihpn.org/resources/ managing-acute-malnutrition-at-scale-a-review-of-donorand-government-financing-arrangements/ (accessed July 2018).

9. Komrska J (2012) Increasing access to ready-to-use therapeutic foods (RUTFs). Field Exchange issue 42, 46; available at https://www.ennonline.net/fex/42/access 
10. World Health Organization (2015) Drinking-water fact sheet. http://www.who.int/mediacentre/factsheets/fs391/ en/ (accessed November 2016).

11. UNICEF \& World Health Organization (2013) Ending Preventable Child Deaths From Pneumonia and Diarrhoea By 2025: The Integrated Global Action Plan for Prevention and Control of Pneumonia and Diarrboea (GAPPD). New York/Geneva: UNICEF/WHO; available at https://www. unicef.org/media/files/Final_GAPPD_main_Report-_EN -8_April_2013.pdf

12. Guerrant RL, Schorling JB, McAuliffe JF et al. (1992) Diarrhea as a cause and an effect of malnutrition: diarrhea prevents catch-up growth and malnutrition increases diarrhea frequency and duration. Am J Trop Med Hyg 47, 1 Pt 2, $28-35$.

13. Jones KD, Thitiri J, Ngari M et al. (2014) Child malnutrition: toward an understanding of infections, inflammation, and antimicrobials. Food Nutr Bull 35, 2 Suppl., S64-S70.

14. Sanchez P, Swaminathan MS, Dobie N et al. (2005) Halving hunger: it can be done (summary version). http://csd. columbia.edu/files/2018/04/UN-Millennium-Project-2005Hunger-Task-Force-Report.pdf (accessed July 2018).

15. UNICEF \& Sindh Bureau of Statistics (2014) Sindh Multiple Indicator Cluster Survey 2014, Key Findings. Karachi: UNICEF and Sindh Bureau of Statistics.

16. Memon M, Soomro MS, Akhtar MS et al. (2011) Drinking water quality assessment in Southern Sindh (Pakistan). Environ Monit Assess 177, 39-50.

17. Agha S \& Williams E (2013) Maternal and Child Health (MCH) Program Indicator Survey 2013: Sindh Province. MNCH Services Component, USAID/Pakistan MCH Program. Karachi: Jhpiego; available at http://www.mchip.net/ sites/default/files/MCH\%20Program\%20Indicator\%20Survey \%20Report $\% 202013 \% 20$ Sindh\%20Province.pdf

18. Action Against Hunger (2012) Nutrition Causal Analysis: Thatta and Dadu District, Sindh Province, Pakistan. https://www.actionagainsthunger.org/publication/2012/ 05/nutrition-causal-analysis-thatta-and-dadu-district-sindhprovince-pakistan (accessed July 2018).

19. The Sphere Project (2011) Sphere Handbook: Humanitarian Charter and Minimum Standards in Disaster Response. Minimum Standards in Food Security and Nutrition. Geneva: Sphere.
20. Ministry of National Health Services, Regulation and Coordination, Government of Pakistan (2014) Pakistan National Guidelines for the Community-Based Management of Acute Malnutrition. Islamabad: Ministry of National Health Services, Regulation and Coordination.

21. Proctor \& Gamble Children's Safe Drinking Water (2018) A simple way to clean water. https://www.csdw.org/csdw/ pur-packet-technology.shtml (accessed June 2018).

22. Centers for Disease Control and Prevention (2014) Safe Water System: Flocculant/Disinfectant Powder. http://www.cdc. gov/safewater/flocculant-filtration.html (accessed June 2018).

23. Action Contre la Faim, ASSRAD \& Institute of Tropical Medicine Antwerp (2017) Efficacité de l'ajout d'une composante WASH ménage dans un programme de traitement ambulatoire de la malnutrition aiguë sévère, Kanem, Tchad. https://www.humanitarianresponse.info/sites/ www.humanitarianresponse.info/files/documents/files/ presentation_etude_washnut_vs_mas_au_tchad_kanem_acf_ refani_event_5_avril_2017.pdf (accessed July 2018).

24. Lantagne D, Quick R \& Mintz E (2011) Household water treatment and safe: storage options in developing countries: a review of current implementation practices. https://www. wilsoncenter.org/sites/default/files/WaterStoriesHousehold. pdf (accessed June 2018).

25. Gruber JS, Ecrumen A \& Colford JM Jr (2014) Coliform bacteria as indicators of diarrheal risk in household drinking water: systematic review and meta-analysis. PLoS One 9, e107429.

26. UNICEF (2012) Evaluation of Community Management of Acute Malnutrition (CMAM): Pakistan Country Case Study. New York: UNICEF; available at https://www.unicef.org/ evaluation/files/Pakistan_CMAM_final_report_11oct2012. pdf

27. World Health Organization (2013) Updates on the Management of Severe Acute Malnutrition in Infants and Children. Geneva: WHO.

28. Burza S, Mahajan R, Marino E et al. (2015) Communitybased management of severe acute malnutrition in India: new evidence from Bihar. Am J Clin Nutr 101, 847-859.

29. World Health Organization (2014) Preventing Diarrhoea Through Better Water, Sanitation and Hygiene: Exposures and Impacts in Low- and Middle-Income Countries. Geneva: WHO. 